\title{
RESISTANCE OF KEYS AS A FACTOR IN REACTION TIMES.'
}

\author{
BY J. V. BREITWIESER, M.A., \\ Assistant in Psychology, 1906-8, Indiana University.
}

The results tabulated in this paper are from records made in the psychological laboratory at Indiana University during the academic year of $1907-8$.

A few records with varying resistances of the reaction key were taken in the summer of Igo6. These showed an increment in the reaction time as the resistance of the reacting key was increased. With a view to further investigate this problem special keys were made and a program for more experimental data was arranged.

As finally formulated, the purpose of the experiment was, (I) To find what difference in the reaction time would be caused by increasing the resistance of the reacting key from 50 to 500 , $I, 000$ and $I, 500$ grams; (2) to find the variation in the number of taps that could be made in five seconds with the same series of resistances; (3) to ascertain the changes in the reaction time for an isolated movement, namely, that of the last joint of the index finger with a series of varying resistances, beginning at I,000 grams, and increasing 500 each time until it went beyond the lifting ability of the muscles involved.

As will be shown more fully below, the measurements for the records in tables $I, 2$ and 3 were made with keys which required a movement like that of the ordinary telegraph key, while for those in No. 4 an ergograph was used.

Apparatus.

The apparatus used for measuring the reaction time was an improved type of pendulum chronoscope with accessories as designed by Professor Bergström. The original form of the

${ }^{1}$ From the Psychological Laboratory of Indiana University, J. A. Bergström, director till August I, 1908 . 
chronoscope is described in the Psychological Review, Vol. VII., No. 5, and that of the improved type with accessories was reported at the meeting of the American Psychological Association at Chicago in 1907.

The key, which was of the break circuit type, was so arranged that the tension of a spring could be brought to bear upon it so that various pressures could be required for the breaking of the circuit.

The signal for the reaction was given by a spring sounder with a scale showing the height of the hammer stroke, thus making it possible to make the strength of stroke perfectly uniform.

To count the number of the tapping movements a recorder like that described by W. L. Bryan in the American Journal of Psychology, November, 1892, was employed. The time for the tapping experiments was kept by a metronome which was checked with a stop watch.

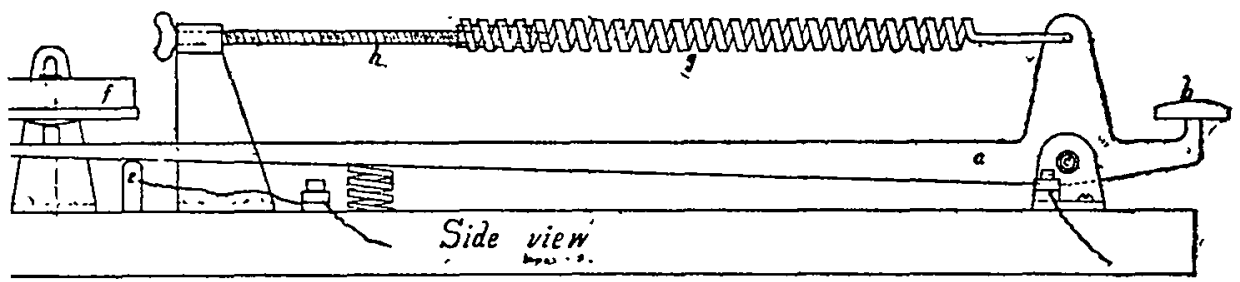

FIG. I.

The key for recording the excess of pressure consisted of a long steel blade $(a)$ (see Fig. I) so mounted that the pressing button $(b)$ was on the short arm of the lever, which was mounted on an axis at $(c)$. Under the long arm of the lever was fastened a short spring which allowed only a small movement for a considerable increase in pressure. This spring did not exert any pressure when the lever was at rest, and served as a resistance for the excess pressure which was measured, as will be described below, by the height of stroke on a kymograph drum. A brass post (e) stood under the long end of the lever where the current was made or broken with the platinum contacts. It was the breaking of this current which stopped the chronoscope in the reaction experiments. The end of the lever was in connection 
with a tambour $(f)$, a tube from which ran to the recording tambour writing on a kymograph drum which recorded the movement of the lever after the connection at $(e)$ was broken. The varying resistances were introduced by the spring $(g)$, the tension of which was varied by the screw $(h)$.

The up stroke of the recording tambour therefore drew a line on the revolving drum which was proportional to the excess pressure exerted on the key. Various measured pressures were then put on the button $(b)$ of the key and the height of the stroke of the recording tambour measured on a scale. With this scale the tambour strokes could be measured and their value recorded in terms of grams of pressure on the key.

The records given in the tables were taken throughout a period of 46 weeks. Usually a full set was taken at a sitting with rests between trials to avoid fatigue which seemed to have much influence especially with the heavier resistances. All records are recorded in thousandths of a second. A few records were discarded where it was known with certainty that the subject had been disturbed by outside influences. Subjects were kept as free as possible from distracting disturbances and were asked in every instance to give as nearly as possible a uniform concentration of effort on work at hand. An attempt was made to have all records made with the same kind of movement so as to have as nearly as possible the same muscles to deal with.

Tables of the results show in each instance the amount of resistance of the key and the corresponding record, also the mean variation. A ' ready' signal was given for every reaction and then the sounder was snapped and the time interval between snap of key and subject's pressing of key recorded. All reaction records are to auditory stimuli and of the motor type.

\section{Program for Daily Experiment.}

In the first series of experiments the resistance of the reaction key was set at 50, 500, $I, 000$, and $I, 500$ grams. A record of ten reactions was taken with each of the respective resistances and then the order of reacting so that ten records were taken again for each resistance, but beginning at 1,500 grams and 
going back to the 50 grams. This programme was followed by all the subjects. They were never allowed to quit without completing this program; thus there were never less than 80 reaction records taken at a sitting. The purpose of this program was to equalize the effect of practice and fatigue on the reactions for the respective resistances.

In the second series of experiments, an ergograph ${ }^{1}$ was employed as a reacting key in connection with the pendulum chronoscope; and so arranged that whenever a certain amount was lifted on the ergograph it recorded the reaction time on the chronoscope in much the same manner as the keys used. This reacting movement had the advantage of isolation and uniformity. In this experiment the index fingers were used and only the end joint allowed to move, the finger being so clamped as to isolate this movement from the rest of the hand.

When the ergograph and the chronoscope were used together the following method was employed. Ten reaction records were taken for every resistance, beginning with I,000 grams as the lightest and increasing the amount by 500 grams each time. This increase was continued up to a point where the subject was unable to lift the weight, then the reverse order was taken with ten readings for every 500-gram variation in weight running from heavy to light. The ergograph resistance is counted as if applied $31.8 \mathrm{~mm}$. from the center of rotation of the joint.

The subjects who served in the experiments wert chosen from the regular students working in the psychological laboratory. For the beginning experiments they were Mr. Smith and Mr. Durgee. The remaining two thirds of the school year Messrs. Miller and Harris acted as subjects. They will be referred to by their respective initials. The writer also acted as a subject in all experiments except where the ergograph was used as a reacting key; he will be designated by the letter $B$.

All subjects had done over twelve weeks of experimental work in psychology. $H$. and $M$. were especially strong men and had shown themselves to be very steady in experimental work. H. was about 27 years old, M. 25. None of the subjects had any preconceived notions as to what the results of the

${ }^{1} \mathrm{~J}$. A. Bergstrom, 'A New Type of Ergograph with a Discussion of Ergograph Experimentation,' Am. Jour. of Psych., Vol. 14, IgO3. 
experiments would be and their effort in all the reactions was to make them as quickly as possible.

From the experiments thus performed we have the following results :

The averages for 125 reactions each for $50,500,1,000$, and 1,500 grams resistance were as follows, the reaction records being made by S., D. and B. on the first type of key used, which did not record the excess pressure. We also have the averages of thirty-five records of the number of taps made in five seconds on the same key. The resistance for the tapping records being the same series as in the reaction records. The records of this table are regarded as preliminary, and are therefore given merely as simple averages.

TABLE I.

\begin{tabular}{|c|c|c|c|c|}
\hline Resistance of Bey. & 5o Grams & 500 Grams. & 1,000 Grams. & 1,500 Grams. \\
\hline  & $\begin{array}{r}I I 2.8 \\
57.8 \\
52.6\end{array}$ & $\begin{array}{l}127.5 \\
56.5 \\
48.8\end{array}$ & $\begin{array}{r}141.8 \\
54.8 \\
44.2\end{array}$ & $\begin{array}{r}149.7 \\
52.3 \\
40.8\end{array}$ \\
\hline
\end{tabular}

In Table II., in which the results are given more in detail, will be found averages for 180 reaction records for each resistance made by H., $M$. and $B$. on the second key, described above, which recorded the excess of pressure in the reaction. A few tapping records are also reported. The same resistances were used as in Table I.

TABLE II.

\begin{tabular}{|c|c|c|c|c|c|c|c|c|}
\hline \multirow{2}{*}{ Resistance of Key. } & \multicolumn{2}{|c|}{ so Grams. } & \multicolumn{2}{|c|}{500 Grams } & \multicolumn{2}{|c|}{$1, \infty \infty$ Grams } & \multicolumn{2}{|c|}{ 2,500 Grums. } \\
\hline & & M. $\nabla$. & & M.v. & & M. v. & & M. V \\
\hline 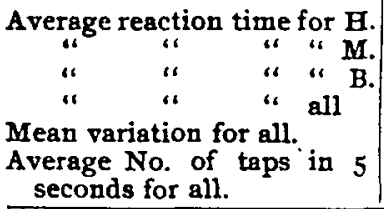 & $\begin{array}{l}71 \cdot 3 \\
98.1 \\
75 \cdot \\
81.7 \\
14.23 \\
49.6\end{array}$ & $\begin{array}{l}12.6 \\
11.8 \\
12 .\end{array}$ & $\begin{array}{r}92.2 \\
116.5 \\
89.6 \\
99.3 \\
10.49 \\
49.2\end{array}$ & $\begin{array}{r}12.6 \\
8.4 \\
10.4\end{array}$ & $\begin{array}{c}102.3 \\
130.5 \\
102.9 \\
111.9 \\
11.22 \\
44.8\end{array}$ & \begin{tabular}{l|} 
I2. \\
I1. 5 \\
ro.4
\end{tabular} & $\begin{array}{c}108.6 \\
139.3 \\
119.8 \\
123.2 \\
10.86 \\
41.8\end{array}$ & $\begin{array}{r}\text { I3. } \\
10.2 \\
9.2\end{array}$ \\
\hline
\end{tabular}

In Table III. will be found averages of the measurements of the excess pressure used. Excess pressure is that above what was necessary to break the circuit which stopped the 
chronoscope index. The results which are given in grams are as follows :

TABLE III.

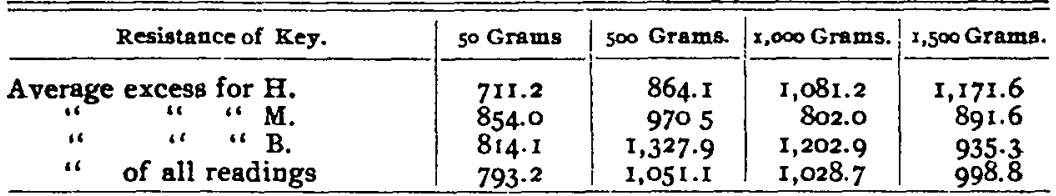

To measure the effect of practice on the excess pressure used, the average excess for each successive day was found, the subject going through the program as stated above. The results are given in Table IV.

TABLE IV.

\begin{tabular}{c|c|c|c}
\hline $\begin{array}{c}\text { Successive } \\
\text { days. }\end{array}$ & B. & M. & H. \\
\hline I & II87.5 & 1493.0 & 1869.37 \\
2 & 880.0 & 1321.25 & 1333.67 \\
3 & II20.0 & 655.62 & 921.25 \\
4 & 911.2 & 605.0 & 661.25 \\
5 & 758.7 & 480.62 & 827.5 \\
6 & 653.7 & 694.37 & \\
7 & 884.3 & & \\
\hline
\end{tabular}

While there are two exceptions in B's averages and one each in M's and H's there appears to be a decrease in the amount of excess on successive day's. Table $\mathrm{V}$. gives the averages of reactions with the ergograph, used as the reacting key, in which the last joint of the index finger was used to produce the movement. This table shows the average of twenty

Resistance in Grams. $35.8 \mathrm{~mm}$. from Center of Rotation of Joint.

1,000
1,500
2,000
2,500
3,000
3,500
4,000
4,500
5,000
5,500
6,000

TAble V.

Reaction Time $\mathbf{M}$

85.0

85.5

94. I

101.8

1033

I 12.3

I 12.8

I 24.9

I54.O
Reaction Time.

H.

88.3

$\log .6$

II7. 3

121.6

136.5

147.3

157.6

164.2

183.3

209.3

216.8 


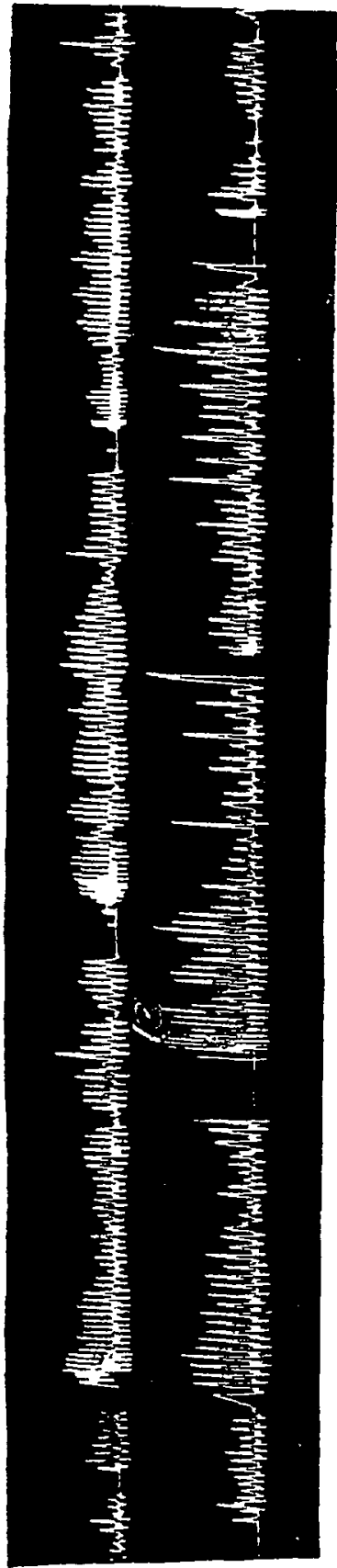

records for each weight. This series was the last taken, the subjects having thus had the practice of all the previous experiments.

Near the limit of the muscle ability to move the weight, the reaction time is evidently nearly double what it is at the beginning.

In Fig. 2 is given a part of the kymograph record of the excess pressure used in tapping. It shows that the excess, or surplus force, was expended in rhythmic or pulselike beats for the curve runs in a wave form. One curve for five seconds began at an excess of five hundred grams which increased in about five taps to an excess of from i 800 to $\mathrm{I}, 200$ grams, then lowered to 50 grams and then rose again to the same excess. The number of taps between the greatest excesses varied from to to 20. The increase or decrease of a series of excess averages is usually regular, yet isolated high or low records also occur.

From the above tables of results we may draw the following conclusions :

r. Reaction time is lengthened or shortened, respectively, when the resistance of the reacting key is increased or decreased within the limits employed. The resistance of the reaction key should therefore be made definite, and should be stated in reaction experiments.

2. The rate of tapping is greates 
with the minimal resistance employed, and decreases as the resistance is increased.

3. The excess force used in a reaction movement does not seem to vary in a marked or definite way with the resistance, in other words, it is largely independent of it.

4. The graphic records for the excess show a tendency towards rhythm, especially in the tapping records.

5. The excess diminishes (more or less regularly) with practice. (Table IV.)

A peculiar fact (perhaps worth noting) is that with the ordinary reaction key M.'s records were longer, while with the ergograph his records were shorter than H.'s. The evidence in detail will be found in Tables II. and V.

Some work on this and closely related problems has already been done. In $189^{2}, M$. Ch. Féré ${ }^{1}$ arrived at the following conclusions :

For one and the same subject the reaction time is longer according as the weight to be lifted is heavier - provided that the weight is not known beforehand. When, however, the weight to be lifted is known to the subject beforehand the length of reaction time does not vary regularly with the weight, but with the capability of the subject to adapt his attention.

It was found however in our experiment, that even though the subject learned the resistances, he still had an increment in his reaction time that increased as the resistance was increased.

Helmholtz found that the total muscular force was not developed instantaneously. Haycraft ${ }^{2}$ of the University of Wales, working upon this problem found that if a muscle be lightly loaded, the muscular force sufficient to raise the weight will be developed say in $\frac{1}{100}$ of a second; if it be loaded with a heavier weight, the greater muscular force requisite to raise it in this case will not be developed say for three or four hundredths of a second.

The amount of pressure was measured by Delabarre ${ }^{3}$ in his experiment on the force and rapidity of reaction movement.

' Comptes Rendus de la Societé de Biologie, gth Series, Vol. IV., I892, pp. 432-435.

'Joumal of Physiol., Vo1. 23.

s Psychol. Rev., Vol. IV. 
He made a study of temperament by taking the reaction time itself, the degree of pressure used by the subject, and the rapidity with which he contracted his reacting muscles. The degree of pressure in this case was measured by the height of a mercury column forced up by the reacting movement. In this experiment as well as the one reported by Féré, we have the force of inertia to overcome at the beginning of the reaction movement while in the experiment reported in this paper all resistances were made by varying tensions of springs, thus reducing the effect of inertia.

It we attempt an explanation of the effects observed one of the possible explanations is that the tip of the finger is capable of quite a good deal of compression and that perhaps some little time was consumed in bringing about this compression before the key was actually moved, which would make the heavy reactions longer than the light. To a slight extent this must be true, but not to a very great extent, especially in the ergograph reactions which followed the same law of increment, for here the finger was placed snugly in a thimble where the compression on all sides was great enough to move the resistances with very little compression.

It has been shown in physiological experiments that muscles have a certain amount of elasticity. Lombard in speaking of the effect of different weights on the gastrocnemius muscle of a frog says: "There can be no movement of the lever until the inertia of the weight has been overcome and the first effect of the contraction is to stretch the muscles, a part of the energy of contraction being changed to elastic force, which on the recoil assists in raising the weight. Thus the myogram may fail to reveal the instant that the contraction process starts.

"Inasmuch as tension increases the activity of muscle protoplasm it is probable that the presence of the weight really hastens the liberation of energy at the same time that it delays the recording of the contraction." This seems to be a very probable explanation for the increase of the reaction time with the increase of the resistance, and may be regarded as one of the chief factors in producing the results recorded above.

A further explanation may be that the nervous impulse itself 
RESISTANCE OF KEYS IN REACTION TIMES. 361

is a thing of volume and requires time' in formation and conduction, and the greater the strength of impulse required the longer the time required to get the requisite amount of stimulation to the nerve ending. The subjects felt the constantly increasing sense of effort the greater the resistance. This may however have been the feeling arising at least in part from the external movements resulting from the effects of the effort put forth. This also is a possible partial explanation of the results. 